\title{
LONG-TERM PHENOMENOLOGICAL MODEL OF PHOSPHORUS AND OXYGEN FOR STRATIFIED LAKES
}

\author{
Steven C. Chapra ${ }^{1 *}$ and Raymond P. Canale ${ }^{2}$ \\ 'Center for Advanced Decision Support for Water and Environmental Systems, The University of \\ Colorado, Campus Box 428, Boulder, CO 80309-0428 and ${ }^{2}$ Civil Engineering, The University of Michigan, \\ Ann Arbor, MI 48109, U.S.A.
}

(First received August 1990; accepted in revised form November 1990)

\begin{abstract}
A budget model is developed to predict the long-term response of a lake to changes in its phosphorus loading. This model computes total phosphorus and hypolimnetic oxygen concentrations, taking sediment-water interactions into account.

The lake is treated as two segments: the water and a surface sediment layer. A total phosphorus budget for the water accounts for inputs due to external loading and recycle from the sediments. It reflects losses due to flushing and settling. The sediment layer gains total phosphorus by settling and loses total phosphorus by recycle and burial. The recycle from the sediments to the water is dependent on the levels of sediment total phosphorus and hypolimnetic oxygen. Hypolimnetic oxygen concentration is estimated with a semi-empirical model.

The model is applied to Shagawa Lake. An analysis is performed to demonstrate how its predictions replicate in-lake changes not possible with simpler phosphorus budget models.
\end{abstract}

Key words - lakes, impoundments, phosphorus, eutrophication, sediments, mathematical model, Shagawa Lake, water quality, restoration

\section{NOMENCLATURE}

General

$A=$ area $\left(\mathrm{m}^{2}\right)$

$p=$ total phosphorus concentration $\left(\mathrm{mg} \mathrm{m}^{-3}\right)$

$Q=$ water flow rate through the lake $\left(\mathrm{m}^{3} \mathrm{yr}^{-1}\right)$

$t=$ time $(\mathrm{yr})$

$V=$ volume $\left(\mathrm{m}^{3}\right)$

$W=$ loading $\left(\mathrm{mg} \mathrm{yr}^{-1}\right)$

$z=$ depth (m).

Other models (e.g. Lorenzen)

$p_{s}=$ sediment exchangeable phosphorus concentration ( $\mathrm{mg} \mathrm{m}^{-3}$ )

$J_{\text {ins }}=$ internal loading $\left(\mathrm{mg} \mathrm{yr}^{-1}\right)$

$K_{1}=$ mass-transfer coefficient from water to sediments $\left(\mathrm{m} \mathrm{yr}^{-1}\right)$

$K_{2}=$ mass-transfer coefficient from sediments to water $\left(\mathrm{m} \mathrm{yr}^{-1}\right)$

$K_{3}=$ fraction in non-exchangeable form

$V_{\mathrm{s}}=$ sediment volume $\left(\mathrm{m}^{3}\right)$

Phosphorus-oxygen model

AHOD $=$ areal hypolimnetic oxygen demand $\left(\mathrm{g} \mathrm{m}^{-2} \mathrm{~d}^{-1}\right)$ $\mathrm{DO}_{\mathrm{h}}=$ hypolimnetic oxygen concentration $\left(\mathrm{g} \mathrm{m}^{-3}\right)$

$\mathrm{DO}_{\mathrm{i}}=$ initial oxygen concentration $\left(\mathrm{g} \mathrm{m}^{-3}\right)$

$\hat{p}=$ predicted total phosphorus concentration $\left(\mathrm{mg} \mathrm{m}^{-3}\right)$

$R R=$ areal phosphorus release rate $\left(\mathrm{mg} \mathrm{m}^{-2} \mathrm{~d}^{-1}\right)$

$t_{\mathrm{s}}=$ time of onset of stratification (d)

$T=$ temperature $\left({ }^{\circ} \mathrm{C}\right)$

$V_{\mathrm{h}}=$ hypolimnetic volume $\left(\mathrm{m}^{3}\right)$

$v_{\mathrm{a}}=$ apparent settling velocity $\left(\mathrm{m} \mathrm{yr}^{-1}\right)$

$v_{\mathrm{b}}=$ sediment burial velocity $\left(\mathrm{m} \mathrm{yr}^{-1}\right)$

$v_{\mathrm{r}}=$ sediment recycle mass-transfer coefficient $\left(\mathrm{m} \mathrm{yr}^{-1}\right)$

$v_{\mathrm{s}}=$ total phosphorus settling velocity $\left(\mathrm{m} \mathrm{yr}^{-1}\right)$

*Author to whom all correspondence should be addressed.

$$
\begin{aligned}
& z_{\mathrm{h}}=\text { hypolimnion thickness }(\mathrm{m}) \\
& \lambda=\text { eigenvalue }\left(\mathrm{yr}^{-1}\right) \\
& \rho=\text { sediment density }\left(\mathrm{g} \mathrm{m}^{-3}\right) \\
& \phi=\text { sediment porosity } \\
& \tau_{\mathrm{w}}=\text { water residence time }(\mathrm{yr})
\end{aligned}
$$

Subscripts

$$
\begin{aligned}
s & =\text { summer } \\
w & =\text { winter } \\
0 & =\text { initial condition } \\
1 & =\text { lake water } \\
2 & =\text { enriched surface sediment }
\end{aligned}
$$

\section{INTRODUCTION}

Over the past decade, most water-quality modeling research has focused on toxic substances and acid rain. As a consequence, conventional modeling areas such as dissolved oxygen and eutrophication have been somewhat neglected.

Today, there are two reasons why conventional pollutants deserve increased attention. First, eutrophication and dissolved oxygen depletion still pose a considerable threat to many receiving waters. Although secondary treatment has been instituted across much of the United States, water-quality standards are not being met in a significant number of our rivers, lakes and estuaries. As a result, many municipalities are being forced to assess costly advanced treatment. Reliable models are required to evaluate these options in a cost-effective manner. Second, although most water-quality models are adequate to predict the impact of primary and secondary effluents, they are not as well-suited to analyze the 
effects of tertiary treatment. In particular, they are usually not adequate to address processes such as plant growth and sediment-water interactions that tend to dominate receiving waters after the installation of primary and secondary treatment.

A case in point is the role of bottom sediments in the recovery of lakes following phosphorus abatement. Bottom sediments have long been acknowledged as a potential source of phosphorus to the overlying waters of lakes and impoundments. As such, sediment feedback could have a significant impact on the recovery of such systems. This would be particularly true in shallow lakes or those with anaerobic hypolimnia.

Although a variety of models has been proposed to address this problem, there is presently no widely accepted framework that effectively characterizes both phosphorus and oxygen during lake recovery. Further, none of the available models are at a level that is well integrated with typical data collection programs for such systems.

In the present paper, we develop a simple modeling framework to address this problem for stratified lakes. The framework is expressly designed for management applications. Before deriving the model, we will first review other research.

\section{REVIEW OF PREVIOUS WORK}

A model of total phosphorus in a well-mixed lake can be written as (Vollenweider, 1969; Chapra, 1975)

$$
V \frac{\mathrm{d} p}{\mathrm{~d} t}=W-Q p-v_{\mathrm{a}} A p
$$

where

$$
\begin{aligned}
V & =\text { lake volume }\left(\mathrm{m}^{3}\right) \\
p & =\text { total phosphorus concentration }\left(\mathrm{mg} \mathrm{m}^{-3}\right) \\
t & =\text { time }(\mathrm{yr}) \\
W & =\text { loading rate }\left(\mathrm{mg}^{-1}\right) \\
Q & =\text { outflow }\left(\mathrm{m}^{3} \mathrm{yr}^{-1}\right) \\
v_{\mathrm{a}} & =\text { apparent settling velocity }\left(\mathrm{m} \mathrm{yr}^{-1}\right) \\
A & =\text { lake surface area }\left(\mathrm{m}^{2}\right) .
\end{aligned}
$$

We will henceforth call equation (1) the "simplesettling model."

If $p=p_{0}$ at $t=0$, the general solution of equation (1) for $W=0$ is (Chapra and Reckhow, 1983)

$$
p=p_{0} \mathrm{e}^{-\lambda t} \text {. }
$$

This solution corresponds to the case where loadings are terminated at time zero. As in Fig. 1, the model predicts that the lake's phosphorus concentration would decrease exponentially to zero following the termination of loadings. The parameter $\lambda$ is an eigenvalue which is defined as

$$
\hat{\lambda}=\frac{Q}{V}+\frac{v_{\mathrm{a}}}{z}
$$

where $z=$ the lake's mean depth (m). Thus, $\lambda$ specifies the rate of the lake's recovery.

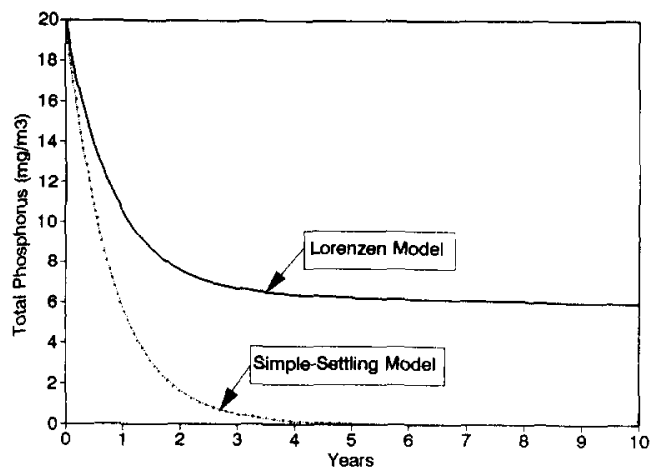

Fig. 1. Comparison of the general solution for the simplesettling and the Lorenzen total P budget models.

An important feature of the model is that it characterizes sedimentation as a one-way loss from the water body. Although this may be a valid assumption for oligotrophic lakes, it has been questioned for more eutrophic systems. In particular, a number of investigators (e.g. Larsen et al., 1975; Ahlgren, 1977; Welch, 1985) have noted that sediment-water interactions could have a strong bearing on the simulation of the transient response of such systems.

As a consequence, several alternative models have been proposed. Larsen et al. (1975) and Ahlgren $(1977,1980)$ have employed a dilution model to simulate the recovery of Shagawa Lake and Lake Norrviken, respectively. This model has the form

$$
V \frac{\mathrm{d} p}{\mathrm{~d} t}=W-Q p
$$

Thus, lake recovery depends totally on flushing. Although the model seemed to provide an adequate characterization of the transient phase of recovery, both applications used measured initial conditions. If the dilution model is employed to predict initial conditions based on a steady-state assumption and measured loadings, they seriously overpredict total phosphorus concentration. Consequently, the model's general applicability is questionable.

Larsen et al. (1979) and Welch et al. (1986) have taken an alternative approach by modifying equation (1) to include a constant sediment release rate as in

$$
V \frac{\mathrm{d} p}{\mathrm{~d} t}=W-Q p-v_{\mathrm{a}} A p+J_{\mathrm{int}}
$$

where $J_{\text {int }}=$ the rate of internal loading ( $\mathrm{mg} \mathrm{yr}^{-1}$ ). Note that Larsen et al. (1979) and Welch et al. (1986) use a volumetric loss rate rather an apparent settling velocity to parameterize losses from the water to the sediments. However, regardless of which mathematical form is employed, the models yield identical results when calibrated to the same data set.]

Equation (5) seems to be adequate for predicting the initial recovery of a eutrophic lake. However, it is problematic for long-term simulations because with time, sediment release should decrease. In fact, Ahlgren (1977) has shown that the sediment release 
rate for Lake Norrviken decreased immediately following its load reduction.

In an attempt to capture the effect of sediment dynamics on lake recovery in a more explicit fashion, several investigators have included a sediment compartment in their models. For example, Lorenzen (1974) and Lorenzen et al. (1976) have developed the following two-compartment model of sedimentwater interactions for total phosphorus,

$$
V \frac{\mathrm{d} p}{\mathrm{~d} t}=W-Q p-K_{1} A p+K_{2} A p_{\mathrm{s}}
$$

and

$$
V_{\mathrm{s}} \frac{\mathrm{d} p_{\mathrm{s}}}{\mathrm{d} t}=K_{1} A p-K_{2} A p_{\mathrm{s}}-K_{1} K_{3} A p
$$

where

$K_{1}=$ mass-transfer coefficient of phosphorus from the water to the sediments $\left(\mathrm{m} \mathrm{yr}^{-1}\right)$

$K_{2}=$ mass-transfer coefficient of exchangeable phosphorus from the sediments to the water (m $\mathrm{yr}^{-1}$ )

$p_{\mathrm{s}}=$ exchangeable phosphorus concentration in the surface sediments $\left(\mathrm{mg} \mathrm{m}^{-3}\right)$

$V_{\mathrm{s}}=$ volume of surface sediments $\left(\mathrm{m}^{3}\right)$

$K_{3}=$ fraction of the total phosphorus input to the sediments that is nonexchangeable.

For cases with constant coefficients, the general solution of equations (6) and (7) is of the form (Chapra and Reckhow, 1983)

$$
p=p_{\mathrm{r} 0} \mathrm{e}^{-\dot{i}_{\mathrm{r}} t}+p_{\mathrm{s} 0} \mathrm{e}^{-\dot{i}_{\mathrm{s}} t}
$$

where the subscripts "f " and "s" designate "fast" and "slow" components of the solution. These components are labeled in this fashion because one of the eigenvalues, $\lambda_{f}$, is typically much greater than the other, $\lambda_{\mathrm{s}}$.

Consequently, as depicted in Fig. 1, the Lorenzen model exhibits a radically different temporal response than the simple-settling model. Initially, the fast component controls the solution. Thus, the lake experiences a rapid initial drop similar to the simplesettling model. However, as the fast component goes to zero, the slow eigenvalue becomes dominant and the lake's recovery is retarded. In essence, sediment feedback prolongs the latter stages of recovery.

Although the Lorenzen framework represented a good attempt at simulating the effect of sediment feedback on lake recovery, it has several deficiencies. First, a clear procedure for estimating its coefficients has never been developed. Second, it does not make explicit allowance for the fact that accelerated feedback of phosphorus is directly linked to anaerobic lake bottom waters. Finally, its assumption that sediment-water interactions take place across the total lake surface area is inaccurate for systems with strong sediment focusing.

Others have attempted to improve Lorenzen's basic approach. Both DiGiano and Snow (1977) and
Kamp-Nielsen (1977) have provided more mechanistic versions. Among other things, these models provide a more concrete foundation for estimating model coefficients on the basis of experimental data. Kamp-Nielsen (1978) and Lung et al. (1986) have extended Lorenzen's approach by characterizing the sediments as a multi-layer system. These frameworks are useful in that the depth of the enriched surfacesediment layer does not have to be specified. Rather, it is computed by the model.

Although these efforts certainly represented improvements, they also added complexity (along with the need for increased measurements) to the Lorenzen framework. In the present paper, we will attempt to develop a model that remedies the deficiencies of Lorenzen's approach while maintaining its simplicity.

\section{MODEL DESCRIPTION}

Our model is dubbed "phenomenological" because its parameters are based on direct field observations rather than on laboratory measurements and theory. Our goal is to develop a model (1) that can be simply calibrated with field measurements made prior to load reductions, and (2) that, employing the calibration parameters, successfully predicts recovery following load reductions.

The framework includes two components: a total phosphorus budget and a model of hypolimnetic oxygen deficit. Each is described briefly in the following sections.

\section{Total phosphorus model}

A sediment-water model for total phosphorus can be written as (Fig. 2)

$$
V_{1} \frac{\mathrm{d} p_{1}}{\mathrm{~d} t}=W-Q p_{1}-v_{\mathrm{s}} A_{2} p_{1}+v_{\mathrm{r}} A_{2} p_{2}
$$

and

$$
V_{2} \frac{\mathrm{d} p_{2}}{\mathrm{~d} t}=v_{\mathrm{s}} A_{2} p_{1}-v_{\mathrm{r}} A_{2} p_{2}-v_{\mathrm{b}} A_{2} p_{2}
$$

where

$$
\begin{aligned}
v_{\mathrm{s}}= & \text { settling velocity of phosphorus from the } \\
& \text { water to the sediments }\left(\mathrm{m} \mathrm{yr}^{-1}\right) \\
A_{2}= & \text { surface area of the deposition zone }\left(\mathrm{m}^{2}\right)
\end{aligned}
$$

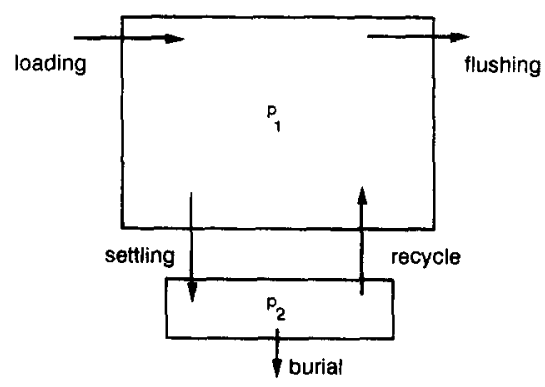

Fig. 2. Schematic diagram of a phosphorus budget model for a lake underlain by sediments. 
$v_{\mathrm{r}}=$ recycle mass-transfer coefficient from the sediments to the water $\left(\mathrm{m} \mathrm{yr}^{-1}\right)$

$v_{\mathrm{b}}=$ burial mass-transfer coefficient from the enriched surface layer to the deep sediments $\left(\mathrm{m} \mathrm{yr}^{-1}\right)$.

Subscripts " 1 " and " 2 " designate the water and the enriched surface sediment layer, respectively.

As with the Lorenzen model, the system is characterized as two segments. However, equations (9) and (10) differ from equations (6) and (7) in the following respects:

(1) The surface sediment area now represents the deposition zone rather than the whole lake bottom. Therefore, all sediment processes take place across a smaller interface - the area of the deposition zone.

(2) Total, as opposed to exchangeable, phosphorus is used to characterize the sediments. This characterization is based on evidence (Nürnberg, 1988) that a positive correlation exists between phosphorus release and sediment total phosphorus concentration. As a first approximation, we have assumed that the relationship is linear with a zero intercept. Although Nürnberg (1988) has fit several other models (linear with non-zero intercept, $\log$ linear, etc.), the linear-zero intercept model conforms generally to her data and represents a simple first-order approximation of the relationship. The advantage of using total instead of exchangeable phosphorus is that comparisons of model calculations with field measurements are more straightforward and readily available.

(3) The loss of phosphorus due to burial is modeled as a function of sediment total phosphorus. This is in contrast to Lorenzen's approach of directly channeling a fraction $\left(K_{3}\right)$ of the settling phosphorus into a nonexchangeable form.

(4) The recycle mass-transfer velocity, $v_{\mathrm{r}}$, is not constant. Rather, it is a function of hypolimnetic dissolved oxygen. If the oxygen concentration is less than a prescribed magnitude, a velocity based on a heightened anaerobic release rate is employed. If the hypolimnetic oxygen level is greater, the velocity is set equal to zero.

\section{Hypolimnetic oxygen model}

A zero-order model is employed here to simulate hypolimnetic oxygen during periods when the lake is stratified,

$$
\mathrm{DO}_{\mathrm{h}}=\mathrm{DO}_{\mathrm{i}}-\frac{\mathrm{AHOD}}{z_{\mathrm{h}}}\left(t-t_{\mathrm{s}}\right)
$$

where

$$
\begin{aligned}
\mathrm{DO}_{\mathrm{h}}= & \text { hypolimnetic dissolved oxygen level } \\
& \left(\mathrm{g} \mathrm{m}^{-3}\right) \\
\mathrm{DO}_{\mathrm{i}}= & \text { initial oxygen concentration at the onset of } \\
& \text { stratification }\left(\mathrm{g} \mathrm{m}^{-3}\right) \\
\mathrm{AHOD}= & \text { areal hypolimnetic oxygen demand } \\
& \left(\mathrm{g} \mathrm{m}^{-2} \mathrm{~d}^{-1}\right) \\
z_{\mathrm{h}}= & \text { average hypolimnion thickness }(\mathrm{m}) \\
t= & \text { time }(\mathrm{d}) \\
t_{\mathrm{s}}= & \text { time of onset of stratification }(\mathrm{d}) .
\end{aligned}
$$

Because there is presently no comprehensive framework to predict AHOD as a function of the quality of the overlying water, empirical approaches are commonly used to estimate this quantity. For example, Rast and Lee (1978) have developed the following correlation $\left(n=34 ; r^{2}=0.38\right)$,

$$
\mathrm{AHOD}=0.0851 \hat{p}^{0.467}
$$

where $\hat{p}$ is lake total phosphorus concentration as predicted by the model (Vollenweider, 1976)

$$
\hat{p}=\frac{W}{Q} \frac{1}{1+\sqrt{\tau_{w}}}
$$

where $\tau_{w}=$ water residence time (yr).

Rather than correlating AHOD with model predictions, we prefer to correlate directly with measured phosphorus concentrations. Using the same data sources as Rast and Lee (1978) we developed the following regression equation $\left(n=26 ; r^{2}=0.51\right)$,

$$
\mathrm{AHOD}=0.086 p_{1}^{0.478} \text {. }
$$

The equation and data are displayed in Fig. 3. Notice that the values of the regression coefficients for equation (12) and (14) are very similar. This suggests that equation (13) is a satisfactory predictor of total phosphorus concentration for these lakes.

For dimictic lakes, an AHOD can also be exerted during winter inverse stratification. In order to simulate depletion for these systems, equation (14) can be

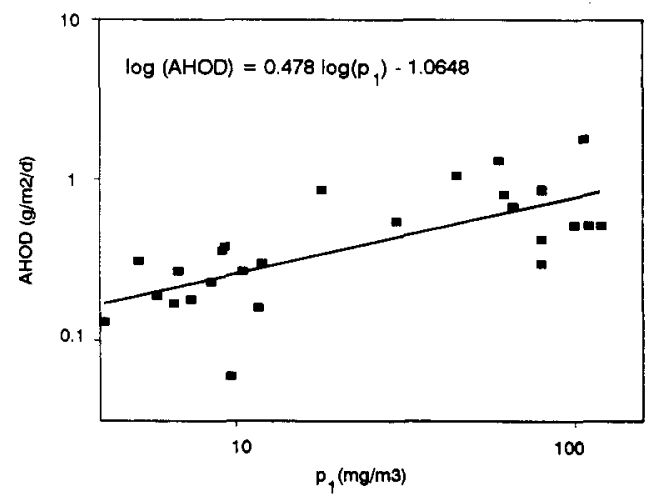

Fig. 3. Areal hypolimnetic oxygen demand $\left(\mathrm{g} \mathrm{m}^{-2} \mathrm{~d}^{-1}\right)$ vs lake phosphorus concentration ( $\mathrm{mg} \mathrm{m}^{-3}$ ). Data from Rast and Lee (1978), Welch and Perkins (1977) and Dillon and Rigler (1974). 
Table 1. Morphometric parameters for Shagawa Lake

\begin{tabular}{lccc}
\hline Parameter & Symbol & Value & Units \\
\hline Volume & $V_{1}$ & $53 \times 10^{6}$ & $\mathrm{~m}^{3}$ \\
Surface area & $A_{1}$ & $9.6 \times 10^{6}$ & $\mathrm{~m}^{2}$ \\
Mean depth & $z_{1}$ & 5.5 & $\mathrm{~m}$ \\
Hypolimnion thickness & $z_{\mathrm{h}}$ & 2.2 & $\mathrm{~m}$ \\
Deposition zone area & $A_{2}$ & $4.8 \times 10^{6}$ & $\mathrm{~m}^{2}$ \\
Surface sediment thickness & $z_{2}$ & 10 & $\mathrm{~cm}$ \\
\hline
\end{tabular}

extrapolated on the basis of temperature using (Thomann and Mueller, 1987)

$$
\mathrm{AHOD}_{\mathrm{w}}=\mathrm{AHOD}_{\mathrm{s}} 1.08^{T_{\mathrm{w}}-T_{\mathrm{s}}}
$$

where $T_{\mathrm{s}}$ is the temperature $\left({ }^{\circ} \mathrm{C}\right)$ at which the summer $\mathrm{AHOD}_{\mathrm{s}}$ is measured and $T_{\mathrm{w}}$ is the temperature $\left({ }^{\circ} \mathrm{C}\right)$ corresponding to the desired winter $\mathrm{AHOD}_{\mathrm{w}}$.

\section{APPLICATION: SHAGAWA LAKE}

Shagawa Lake, Minn., is an ideal setting to illustrate the model. This is because it is one of the first systems where sediment feedback was recognized as being important. In addition, it has been the subject of numerous studies and, hence, there is a large quantity of information available for model calibration.

\section{Calibration}

Model calibration is based on the extensive data reported by Larsen, Malueg and colleagues (e.g. Larsen and Malueg, 1976, 1981; Larsen et al., 1975, 1979, 1981; Malueg et al., 1975; Bradbury and Waddington, 1973).

The following calibration is for the pre-treatment period (1967-1972). It is assumed that the lake was at a steady state during this time frame. The implications of this assumption will be discussed in a later section.

Morphometry. Morphometric information for Shagawa Lake is summarized in Table 1. The deposition zone area conforms to the $6 \mathrm{~m}$ depth contour (Larsen et al., 1981) which also represents the approximate depth of the thermocline.
Hydrology and phosphorus budgets. Hydrologic and loading information from 1967 through 1979 is summarized in Table 2. In addition, we have included other terms pertaining to the lake's total phosphorus budget in the table.

Concentrations. Total phosphorus concentrations from 1967 through 1979 are summarized in Table 2. Pre-treatment inflow concentrations (1967-1972) were over $80 \mathrm{mg} \mathrm{m}^{-3}$. Following load reductions in 1973 , the inflow concentration has been reduced to about $20 \mathrm{mg} \mathrm{m}^{-3}$.

Aside from direct measurement of in-lake concentration, we have also included outflow concentration in Table 2. Outflow concentrations are generally about $90 \%$ of in-lake concentrations. In either case, pre-treatment total phosphorus levels in the lake were approx. $50-60 \mathrm{mg} \mathrm{m}^{-3}$. After 1973, both in-lake and outflow concentrations dropped to levels of $25-35 \mathrm{mg}$ $\mathrm{m}^{-3}$.

Stratification. Shagawa Lake begins the summer stratified period in the beginning of June. Fall overturn occurs in mid-September. The lake is covered with ice from the last week in November to the beginning of May during which inverse stratification has been observed (Larsen and Malueg, 1976).

Oxygen parameters. The areal hypolimnetic oxygen demand is computed [using equation (14)] at the beginning of each year on the basis of the average total phosphorus concentration for the previous year. This summer rate is transformed to a winter rate using equation (15).

The initial hypolimnetic oxygen level $\left[\mathrm{DO}_{\mathrm{i}}\right.$ from equation (11)] is taken as $8 \mathrm{mg} \mathrm{l}^{-1}$ for both summer and winter stratified periods. Although anaerobic feedback is usually triggered when the oxygen level at the bottom of the hypolimnion falls below $1 \mathrm{mg} \mathrm{l}^{-1}$ (Mortimer, 1971), we used a level of $1.5 \mathrm{mg} \mathrm{1}^{-1}$ to activate heightened release. This was done to compensate for the fact that the hypolimnion is actually not well mixed. Therefore, heightened release will begin prior to the average oxygen concentration dropping below $1 \mathrm{mg} \mathrm{I}^{-1}$.

Table 2. Flows, loads and concentrations for Shagawa Lake

\begin{tabular}{|c|c|c|c|c|c|c|c|}
\hline \multirow[b]{2}{*}{ Year } & \multirow{2}{*}{$\begin{array}{c}\text { Outflow } \\
\left(10^{6} \mathrm{~m}^{3} \mathrm{yr}^{-1}\right)\end{array}$} & \multicolumn{3}{|c|}{ Loads ( $\mathrm{kg} \mathrm{yr}^{-1}$ ) } & \multicolumn{3}{|c|}{ Concentrations $\left(\mathrm{mg} \mathrm{m}^{-3}\right)$} \\
\hline & & Input & Output & Retained & Inflow* & Outflow & In-lake \\
\hline 1967 & 49.6 & 6042 & 2930 & 3112 & 121.8 & 59.1 & \\
\hline 1968 & 100.4 & 6879 & 6200 & 679 & 68.5 & 61.8 & \\
\hline 1969 & 83.7 & 6777 & 5490 & 1287 & 81.0 & 65.6 & \\
\hline 1970 & 120.8 & 7372 & 6140 & 1232 & 61.0 & 50.8 & \\
\hline 1971 & 93.3 & 6839 & 4680 & 2159 & 73.3 & 50.2 & 47.4 \\
\hline 1972 & 62.1 & 6240 & 3140 & 3100 & 100.5 & 50.6 & 54.1 \\
\hline 1967-1972 average & 85.0 & 6692 & 4763 & 1928 & 84.4 & 56.3 & \\
\hline 1973 & 91.5 & 2140 & 4310 & -2170 & 23.4 & 47.1 & 48.7 \\
\hline 1974 & 80.4 & 1490 & 2180 & -690 & 18.5 & 27.1 & 31.4 \\
\hline 1975 & 63.5 & 1020 & 1670 & -650 & 16.1 & 26.3 & 29.3 \\
\hline 1976 & 37.6 & 890 & 930 & -40 & 23.7 & 24.7 & 29.5 \\
\hline 1977 & 84.3 & 1290 & & & 15.3 & & 33.6 \\
\hline 1978 & 62.6 & 1160 & & & 18.5 & & 28.3 \\
\hline 1979 & 68.6 & 1460 & & & 21.3 & & \\
\hline 1973-1979 average & & 1350 & & & 19.5 & & \\
\hline 1967-1979 average & 76.8 & & & & & & \\
\hline
\end{tabular}

*Calculated as loading divided by outflow 
Sediment thickness. Core measurements indicate that high phosphorus levels $(>0.1 \%$ total $\mathrm{P}$ ) are limited to the top $10 \mathrm{~cm}$ of the sediments (Bradbury and Waddington, 1973; Larsen et al., 1981).

Burial velocity. The average total phosphorus content of the surficial sediments is approx. 0.2 $\% \mathrm{P}$ (Larsen et al., 1981). Assuming that porosity is 0.9 and sediment density is $2.5 \mathrm{~g} \mathrm{~cm}^{-3}$, this is equivalent to a sediment total phosphorus concentration of

$p_{2}=0.002(1-0.9) 2.5 \times 10^{6}\left(10^{3}\right)=500,000 \frac{\mathrm{mg}}{\mathrm{m}^{3}}$.

For the period from 1967 to 1972 about $1928 \mathrm{~kg}$ $\mathrm{yr}^{-1}$ of total phosphorus was retained in the lake (Table 2). If it is assumed that this is approximately equivalent to the amount of phosphorus that is incorporated into the deep sediments, the burial velocity can be estimated as

$$
\begin{aligned}
v_{\mathrm{b}} & =\frac{W_{\text {retained }}}{A_{2} p_{2}} \\
& =\frac{1928 \times 10^{6}}{\left(4.8 \times 10^{6}\right) 500,000}=8.03 \times 10^{-4} \frac{\mathrm{m}}{\mathrm{yr}} .
\end{aligned}
$$

Settling velocity. For the present simulation, we will use a value based on observations reported by Larsen et al. (1979, 1981). Following ice-out and fall overturn, the total phosphorus in the water column of Shagawa Lake decreases at a rate of approx. $2.1 \%$ per day. For a mean depth of $5.5 \mathrm{~m}$, this translates into a settling velocity of approx. $42.2 \mathrm{~m} \mathrm{yr}^{-1}$.

Recycle velocity. If it is assumed that the active sediment layer was approximately at steady state in the late 1960 s, the recycle mass transfer can be determined as $W_{\text {recycle }}=W_{\text {settling }}-W_{\text {burial }}=$ $11410-1928=9476 \mathrm{~kg} \mathrm{yr}^{-1}$. This corresponds to a summer anaerobic recycle velocity of $v_{\mathrm{r}}=$ $0.0115 \mathrm{~m} \mathrm{yr}^{-1}$ and a winter velocity of $v_{\mathrm{r}}=$ $0.00494 \mathrm{~m} \mathrm{yr}^{-1}$.

The summer velocity can also be expressed as a release rate in order to compare it with measure-

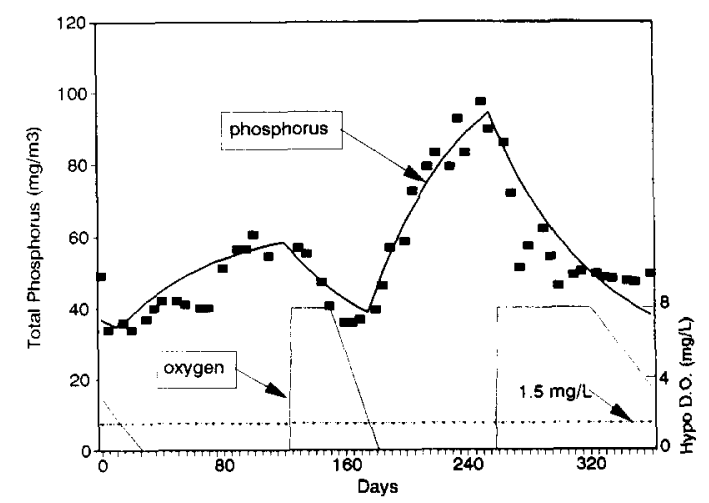

Fig. 4. Plot of phosphorus and oxygen in the pre-treatment period (1967-1972) for Shagawa Lake. The data are for 1972 (Larsen et al., 1979).

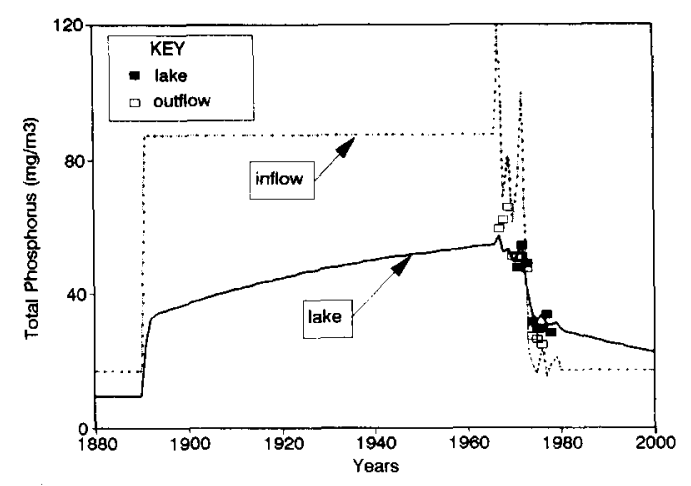

Fig. 5. Long-term total phosphorus concentration for Shagawa Lake as simulated by the phosphorusoxygen model (thick line). A plot of inflow concentration is superimposed (thin line) for comparison.

ments. Assuming that $p_{2}=500,000 \mathrm{mg} \mathrm{m}^{-3}$, the velocity translates into a release rate of

$$
R R=0.0115 \frac{\mathrm{m}}{\mathrm{yr}}\left(500,000 \frac{\mathrm{mg}}{\mathrm{m}^{3}}\right) \frac{1 \mathrm{yr}}{365 \mathrm{~d}}=15.75 \frac{\mathrm{mg}}{\mathrm{m}^{2} \mathrm{~d}} .
$$

The bulk of measured rates fall in the range from 8 to $16 \mathrm{mg} \mathrm{m}^{-2} \mathrm{~d}^{-1}$ (Larsen et al., 1981). Our rate lies at the high end of this range because our estimate is a gross rate of release whereas the measurements represent net values. Taking into account the fact that our model computes settling and recycle concurrently, we can express our value as a net rate of $9.3 \mathrm{mg} \mathrm{m}^{-2} \mathrm{~d}^{-1}$. Consequently, when formulated in commensurate terms, our release rate is actually closer to the lower bound of the measurements.

\section{Simulation}

Annual case. Figure 4 shows our simulation results for a single year during the steady-state calibration period. Data shown are for 1972 (Larsen et al., 1979). Notice how the phosphorus increases due to the heightened release rate when the oxygen level falls below $1.5 \mathrm{mg} \mathrm{l}^{-1}$. A better fit could have been accomplished by additional tuning of the parameters or by allowing the model parameters to vary seasonally. However, considering the simplicity of the present calibration process, Fig. 4 is judged to be an adequate approximation of the general trend of the data.

Long-term historical case. In order to obtain some perspective on the long-term dynamics of Shagawa Lake, a simulation was performed for the period from 1880 to 2000 . Actual flows were used for the period from 1967 to 1979 (Table 2). An average flow is employed for all other years.

Because measurements were not made prior to 1967 , an idealized long-term loading scenario was developed (Fig. 5). Measured loadings are employed for the period from 1967 to 1979 (Table 2). Before 1890 and after 1979, an average "natural" loading of $1311 \mathrm{~kg} \mathrm{yr}^{-1}$ (Larsen et al., 1975) is assumed to apply. 


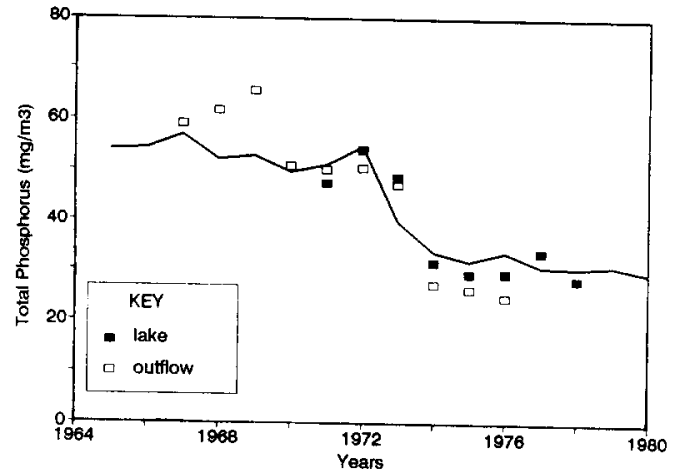

Fig. 6. Recent total phosphorus concentration for Shagawa Lake as simulated by the phosphorus-oxygen model.

In 1890, the town of Ely was established in the lake watershed. From 1890 to the present, the town's population has been relatively stable. An idealized scenario is employed to characterize the town's contribution. The scenario assumes that immediately upon Ely's establishment, the loadings increased stepwise to the high average levels of the late 1960s. Although the actual loading was undoubtedly different than this idealization, in the absence of direct measurements, it is considered to be an adequate first approximation.

The results of the long-term simulation along with measured data are shown in Fig. 5. The plot indicates that after the 1973 load reduction, the lake experienced an immediate quick response. However, by 1974 the lake's recovery slowed significantly due to feedback of phosphorus from the sediments.

Aside from its simplicity, the use of a step increase to characterize the historical loading scenario allows a clearer visualization of the model's response characteristics. As in Fig. 5, the model shows an immediate sharp increase in 1890 following the step load increase. Then, as the slow eigenvalue begins to dominate, the remainder of the increase proceeds at an extremely slow rate (about $0.2 \mathrm{mg} \mathrm{m}^{-3}$ per year). By the early 1960s, the lake was just beginning to approach a steady-state. Although it had not totally reached a steady state at that time, it seems to have been close enough to make our calibration acceptable.

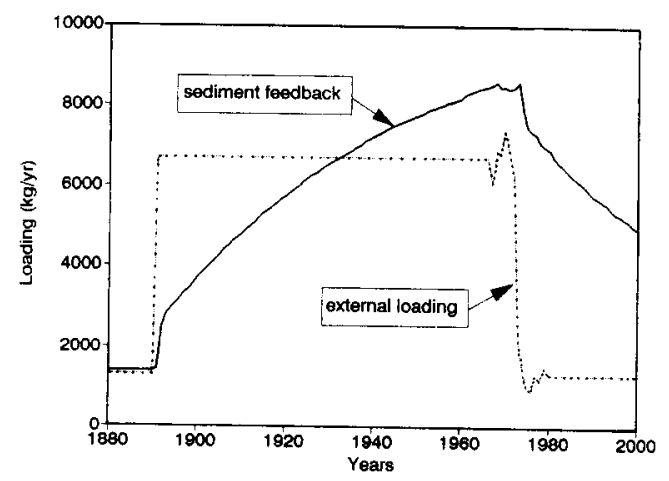

Fig. 7. Long-term trends of sediment recycle (thick line) of phosphorus for Shagawa Lake as simulated by the phosphorus-oxygen model. The external loading is superimposed (thin line) for comparison.

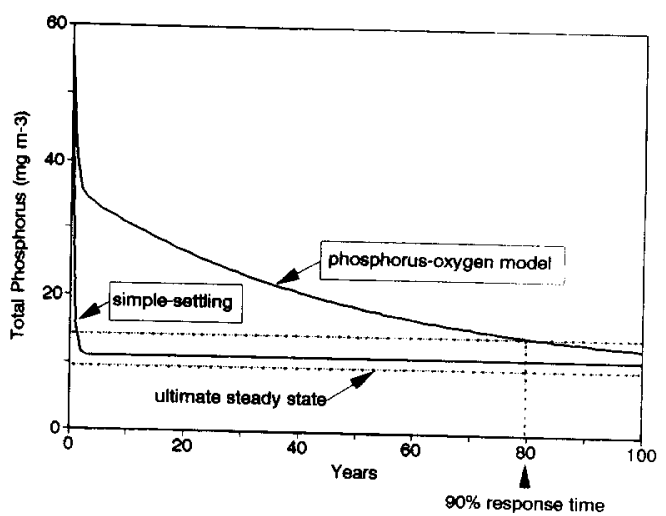

Fig. 8. Comparison of response characteristics of the simple-settling and the phosphorus-oxygen model for Shagawa Lake.

Short-term historical case. The simulation results and data for the recent past are depicted in Fig. 6. The adequacy of the simulation can be assessed by three features of the response. First, the model approximately matches the pre-diversion levels of $50-60 \mathrm{mg} \mathrm{m}^{-3}$. Second, the initial rapid drop of about $25 \mathrm{mg} \mathrm{m}^{-3}$ is close to the observed drop. Finally, the rate of the subsequent retarded recovery is quite close in the data. Considering that the model parameters are untuned, these results are encouraging.

Sediment feedback. Figure 7 is a plot of external and internal loadings as calculated by the model. Notice how the internal sediment feedback load takes many decades to build up to the high levels observed during the 1960s. Also notice how after advanced treatment was installed in 1973, the sediment feedback experienced a small abrupt drop followed by a very gradual decrease. This may explain why the constant sediment feedback model [equation (5)] has performed well for Shagawa (Larsen et al., 1979) as well as other systems such as Lake Sammamish (Welch et al., 1986). However, it also indicates that, although the constant feedback model would be adequate for short-term projections (i.e. less than a decade), long-term predictions would have to account for the gradual decline in sediment release.

General response characteristics. An effort to gain additional insight into the model's temporal response is provided in Fig. 8. This plot shows simulation results for the case where the initial conditions are set at the steady-state pre-treatment conditions. At time zero, the loading is immediately dropped to the low post-treatment natural level. Thus, this plot is the opposite of the step increase in 1890. In addition, we have also included the same simulation for the simplesettling model [equation (1)]. Inspection of Fig. 8 leads to a number of observations:

(1) Because of the absence of sediment feedback, the simple-settling model exhibits a speedy recovery with a ninety percent response time, $t_{90}$, of less than 2 years. 
(2) The phosphorus-oxygen model manifests a much slower recovery due to sediment feedback. This effect extends the $t_{90}$ to about 80 years.

(3) The ultimate recovery of the models is different. Whereas the linear simple-settling model reaches a steady-state of about $11 \mathrm{mg} \mathrm{m}^{-3}$, the nonlinear phosphorus-oxygen model eventually stabilizes at about $9.5 \mathrm{mg} \mathrm{m}^{-3}$. This effect is due to the fact that the release rate in the latter model is dependent on hypolimnetic oxygen. Consequently, as conditions improve, the release rate decreases nonlinearly.

\section{DISCUSSION}

The general implications of the foregoing results are clear. If our model is correct, systems such as Shagawa Lake would take many years to become totally "saturated" with phosphorus. However, once thoroughly polluted, they would take a similarly long period to be cleansed. Therefore, for lakes that have only recently been subject to cultural eutrophication, load reductions should be implemented in a timely fashion. For lakes that have a long history of abuse, in-lake treatment procedures such as sediment dredging, chemical treatment and artificial aeration could represent the only viable alternatives if immediate recovery is desired. Of course, such treatments would also have to be evaluated on the basis of cost and how they impacted the lake's current uses.

The present model has been shown to do a credible job of simulating the recovery of Shagawa Lake. The model has the advantage of having relatively few parameters. This facilitates direct estimation of all model parameters using field and laboratory measurement techniques. Such direct measurement of all parameters serves to increase the overall reliability of the model and reduces propagated error due to parameter uncertainty.

Future research will be devoted to four specific areas:

(1) Application of the framework to other systems. We intend to test the model by applying it to other systems such as Lakes Washington and Sammamish.

(2) Investigation of the use of a multi-layer approach (Lung et al., 1976) to characterize the sediments. This will necessitate a division of sediment phosphorus into solid and dissolved forms.

(3) Development of ways in which the present framework can be closely tied to a lake monitoring and parameter identification measurement program.

(4) In our future research, we intend to study the temporal response characteristics of our model. Clearly, the basic reason for the slow response of our model is that the sediment layer's purg- ing mechanisms, recycle and burial, are small relative to its thickness. However, as illustrated by O'Connor (1988) for a linear sedimentwater toxicant model, a definitive analysis of temporal response for such systems is not simple. We will attempt such an analysis in order to more precisely understand which mechanisms dictate the slow recovery of our nonlinear sediment-water model.

In conclusion, we have developed a preliminary framework for assessing the impact of sediment feedback of phosphorus on long-term lake recovery. The results are encouraging enough to merit further investigation. If successful, the framework could prove useful in simulating the recovery of lakes that have been subjected to serious cultural eutrophication.

Acknowledgements - We would like to thank the Center for Advanced Decision Support for Water and Environmental Systems (CADSWES) and the Upstate Freshwater Institute (UFI) for their support of this research. Thanks to Jean Boyer and Rob Runkel for their careful readings of this manuscript. We also appreciate the discussions we shared with Steve Effler and Marty Auer on sediment-water interactions. Finally, this manuscript could not have been developed without the benefit of the many fine papers written by our colleagues Phil Larsen, Kenneth Malueg and Gertrud Nürnberg.

\section{REFERENCES}

Ahlgren I. (1977) Role of sediments in the process of recovery of a eutrophicated lake. In Interactions Between Sediments and Fresh Water (Edited by Golterman H. L.), pp. 372-377. Junk, The Hague.

Ahlgren I. (1980) A dilution model applied to a system of shallow eutrophic lakes after diversion of sewage effluents. Arch. Hydrobiol. 89, 17-32.

Bradbury J. and Waddington J. C. B. (1973) Stratigraphic record of pollution in Shagawa Lake, northeastern Minnesota. In Symposium on Quartenary Plant Ecology (Edited by Birks H. J. B. and West R. G.), pp. 289-307. Blackwell, London.

Chapra S. C. (1975) Comment on "An empirical model of estimating the retention of phosphorus in lakes" by W. B. Kirchner and P. J. Dillon. Wat. Resour. Res. 11, 1033-1034.

Chapra S. C. and Reckhow K. H. (1983) Engineering Approaches for Lake Management, Vol. 2, Mechanistic Modeling. Butterworth, Woburn, Mass.

DiGiano F. A. and Snow P. D. (1977) Consideration of phosphorus release from sediments in a lake model. In Interactions Between Sediments and Fresh Water (Edited by Golterman H. L.), pp. 318-323. Junk, The Hague.

Dillon P. J. and Rigler F. H. (1974) The phosphoruschlorophyll relationship in lakes. Limnol. Oceanogr. 19, 767-773.

Kamp-Nielsen L. (1977) Modeling the temporal variation in sediment phosphorus fractions. In Interactions Between Sediments and Fresh Water (Edited by Golterman H. L.), pp. 277-285. Junk, The Hague.

Kamp-Nielsen L. (1978) Modeling the vertical gradients in sedimentary phosphorus fractions. Verh. int. Verein. Limnol. 20, 720-727.

Larsen D. P. and Malueg K. W. (1976) Limnology of Shagawa Lake, Minnesota, prior to reduction of phosphorus loading. Hydrobiologia 50, 177-189. 
Larsen D. P. and Malueg K. W. (1981) Whatever became of Shagawa Lake? In Restoration of Lakes and Inland Waters. International Symposium on Inland Waters and Lake Restoration, pp. 67-72. U.S. Environmental Protection Agency, EPA-440/4-81-010.

Larsen D. P., Malueg K. W., Schults D. W. and Brice R. M. (1975) Response of eutrophic Shagawa Lake, Minnesota, U.S.A. to point source phosphorus reduction. Verh. int. Verein. Limnol. 19, 884-892.

Larsen D. P., Schults D. W. and Malueg K. W. (1981) Summer internal phosphorus supplies in Shagawa Lake, Minnesota. Limnol. Oceanogr. 26, 740-753.

Larsen D. P., Van Sickle J., Malueg K. W. and Smith P. D. (1979) The effect of wastewater phosphorus removal on Shagawa Lake, Minnesota: phosphorus supplies, lake phosphorus, and chlorophyll a.Wat. Res. 13, 1259-1272.

Lorenzen M. W. (1974) Predicting the effects of nutrient diversion on lake recovery. In Modeling the Eutrophication Process (Edited by Middlebrooks et al.), pp. 205-210. Ann Arbor Science, Ann Arbor, Mich.

Lorenzen M. W., Smith D. J. and Kimmel L. V. (1976) A long-term phosphorus model for lakes: application to Lake Washington. In Modeling Biochemical Processes in Aquatic Ecosystems (Edited by Canale R. P.), pp. 75-91. Ann Arbor Science, Ann Arbor, Mich.

Lung W. S., Canale R. P. and Freedman P. L. (1976) Phosphorus models for eutrophic lakes. Wat. Res. 10, 1101-1114.

Malueg K. W., Larsen D. P., Schults D. W. and Mercier H. T. (1975) A six year water, phosphorus and nitrogen budget of Shagawa Lake. J. envir. Qual. 4, 236-242.

Mortimer C. H. (1971) Chemical exchanges between sediments and water in the Great Lakes-speculation on probable regulatory mechanisms. Limnol. Oceanogr. 16, 387-404.

Nürnberg G. K. (1988) Prediction of phosphorus release rates from total and reductant-soluble phosphorus in anoxic lake sediments. Can. J. Fish. Aquat. Sci. 45, 453-462.

O'Connor D. J. (1988) Models of sorptive toxic substances in freshwater systems. II: Lakes and reservoirs. J. envir. Engng Am. Soc. civ. Engrs 114, 533-551.

Rast W. and Lee G. F. (1978) Summary Analysis of the North American (U.S. Portion) OECD Eutrophication Project: Nutrient Loading-Lake Response Relationships and Trophic State Indices. U.S. Environmental Protection Agency, EPA-600/3-78-008.

Thomann R. V. and Mueller J. A. (1987) Principles of Surface Water Quality Modeling and Control. Harper \& Row, New York.

Vollenweider R. A. (1969) Möglichkeiten und Grenzen elementarer Modelle der Stoffbilanz von Seen. Arch. Hydrobiol. 66, 1-36.

Vollenweider R. A. (1976) Advances in defining critical loading levels for phosphorus in lake eutrophication. Mem. Ist Ital. Idrobiol. 33, 53-83.

Welch E. B. (1985) The eventual recovery of Lake Sammamish following phosphorus diversion. J. Wat. Pollut. Control. Fed. 57, 977-978.

Welch E. B. and Perkins M. A. (1979) Oxygen deficitphosphorus loading relation in lakes. J. Wat. Pollut. Control. Fed. 51, 2823-2828.

Welch E. B., Spyridakis D. E., Shuster J. I. and Horner R. R. (1986) Declining lake sediment phosphorus release and oxygen deficit following wastewater diversion. J. Wat. Pollut. Control Fed. 58, 92-96. 